\title{
STRUKTUR DAN FUNGSI PANTUN TRADISI “PALANG PINTU” SANGGAR BANG BENS DI RAWA BELONG JAKARTA BARAT
}

\author{
Muhammad Dwi Juniarto \\ Universitas Udayana \\ Posel: muhammaddwijuniarto@gmail.com \\ Artikel dikirim: 11 Agustus 2021; Diterima: 21 Sepetember 2021

\section{STURUCTURE AND FUNCTION OF PANTUN PALANG PINTU TRADITION OF SANGGAR BANG BENS IN RAWA BELONG WEST JAKARTA}

\begin{abstract}
This article is about Sturucture and Function of Pantun at Betawi tribe in Rawa Belong West Jakarta. The choice of this topic departs from the author's interest in the form and structure of Betawi rhymes. The formulation of the problem is focused on two things. First, the structure of the Betawi rhyme and the social functions of the rhyme for the Betawi people. The theory used is the theory of structural strata norm of Roman Ingarden and the theory of function of Alan Dundes and William R. Bascom. The method used is to listen and record with the technique of Listening Free Libat Cakap. Analysis of Betawi rhymes shows variations in structure that are different from conventional rhymes and rhymes from other regions. Layers of sound Assonance or repetition of vowels dominated by vowel e $\{\partial\}$, Alliteration or repetition of consonant sounds dominated by ng $\{\eta\}$, rhyme dominated by $\{$ er-er\} continuous rhyme and cross rhyme \{an-i-an\}. Euphemism, sarcasm and hyperbole in rhymes are found and dominate. The function as a means of coercion and supervisor of norms in society is very thick in Betawi rhymes. The discovery of the intensity of the entertainment function in words that form distinctive stanzas and rhymes.
\end{abstract}

Keywords: pantun, structure, function, community Betawi

\section{PENDAHULUAN}

Selama ratusan tahun berbaur dengan masyarakat Betawi, akhirnya pantun menjadi sebuah penyampaian karakter masyarakat Betawi, dengan memodifikasi syair berbahasa betawi yang terkesan cuek dan apa adanya. Hingga setelah kemerdekaan, banyak bermunculan seniman Betawi yang membawa perubahan isi pantun dengan gaya khas penyampaian masyarakat Betawi sampai saat ini (jakarta.go.id/artikel/konten/pantunbetawi). Lazimnya saat ini pantun konvensional dan pantun-pantun beberapa daerah lain di indonesia memiliki ciri struktur yang sama, yaitu 1) Terdiri dari 4 baris dan 4 larik, 2) Setiap baris memiliki 8-12 suku kata, 3) Kata di akhir baris bersajak a-b-a-b atau a-a-a-a, 4) Baris pertama dan kedua dinamakan sampiran dan baris kedua dinamakan isi, 5) Sampiran dan isi merupakan hal yang terpisah biasanya tidak saling berhubungan, 6) Pantun merupakan karya yang sifatnya anonim, karena tidak diketahui pengarangnnya (https://belajargiat.id/pantun/). Ciri-ciri pantun tersebut populer dan dijadikan sebagai kaidah pantun dikurikulum pembelajaran, namun ciri-ciri 
pantun tersebut bertolak belakang dengan penelitian yang dilakukan oleh sarjana sastra klasik di Yugoslavia yaitu Milman Parry dan Albert Bates Lord dengan teori formulanya, mereka membuktikan bahwa struktur sastra lisan selalu berubah-ubah, lincah dan hidup karena selalu diciptakan dan dihayati kembali sesuai dengan daya cipta pembawa maupun penikmatnya (Teeuw, 1988: 299 via Taum, 2011: 68), menurut Lord konsep kelisanan dalam teori formula tidak hanya dimaknai sebagai presentasi lisan, tetapi juga dimaknai sebagai komposisi "selama" terjadinya penampilan secara lisan. Adanya penampilan lisan memperkuat daya pikat cerita dan menimbulkan dampak sosial bagi masyarakat.

Palang- Pintu merupakan salah satu penampilan lisan yang masih hidup dan menjadi wadah bagi Pantun Betawi. Menurut Ruth Finnegan puisi lisan memiliki fungsi yaitu: 1) untuk mempertahankan status masyarakat; 2) sebagai salah satu fungsi narasi lisan; 3) sebagai tindakan sosialitas; dan 4) sebagai sarana rekreasi setelah sclesai bekerja (dalam Sudikan, 2001:109-116). Dengan begitu adanya penampilan lisan fungsi yang dimiliki oleh pantun Betawi akan sangat berdampak langsung bagi masyarakat.

Penelitian sebelumnya mengenai pantun pernah dilakukan oleh Siti Rojab Dian Puspitasari dari Universitas Indonesia (UI) dengan judul skripsi "Pantun Betawi dalam siaran Bensradio: Tinjauan Fungsi dan Amanat". Fakultas Ilmu Pengetahuan Budaya, 2008. Pada penelitian ini Puspitasari memberikan gambaran mengenai fungsi dan amanat pantun. Persamaan penelitian dan penulis dengan Puspitasari, yaitu sama-sama meneliti pantun Betawi dan perbedaan pada peneliti penulis dengan penelitian Puspitasati, yaitu subjek kajiannya berbeda. Puspitasari meneliti pantun Betawi dalam siaran Bensradio: tinjauan fungsi dan amanat, sedangkan penulis meneliti tentang struktur dan fungsi pantun dalam tradisi Palang Pintu, kemudian penelitian Maman Mahayana dalam Jurnal Kritik 06/2013; volume 04, III (Januari-Juni 2013): 85-100; dengan judul “Pantun sebagai Potret Sosial-Budaya Tempatan: perbandingan Pantun Melayu Jawa, Madura dan Betawi". Pada penelitian ini Maman Mahayana membandingkan pantun Melayu, Jawa, Madura, dan Betawi serta menunjukan perbedaan dalam fungsi dan ekspresi dalam konten dan sampiran. Persamaan penelitian penulis dengan penelitain Mahayana, yaitu sama-sama meneliti pantun Betawi dan penelitian penulis dengan penelitian Mahayana, yaitu subjek kajiannya berbeda. Mahayana meneliti pantun sebagai potret sosial-budaya tempatan: perbandingan pantun Melayu, jawa, Madura dan Betawi sedangkan penulis meneliti struktur dan fungsi pantun dalam tradisi Palang Pintu.

Teori yang digunakan sebagai dasar kajian adalah teori struktural yang mengacu kepada teori strata norma Roman Ingarden dan teori fungsi yang mengacu kepada teori Willian R. Bascom dan Alan Dundes. Kedua teori tersebut memperkuat analisis dalam 
membedah struktur pantun betawi dan menghasilkan sudut pandang internal dan eksternal.

Metode yang digunakan dalam penelitian ini adalah kualitatif yang bersifat deskriptif. Metode kualitatif memberikan perhatian terhadap data ilmiah data dalam hubungannya dengan konteks keberadaanya, sumber data penelitian ini adalah percakapan lisan yang sudah diubah menjadi teks tertulis. Dalam ilmu sastra sumber datanya adalah karya, naskah, data penelitiannya, sebagai data formal adalah kata-kata, kalimat dan wacana (Ratna, 2009:47). Setelah data dikumpulkan kemudian dilanjutkan dengan tahap analisis, langkah-langkah yang diambil peneliti guna melakukan analisis data adalah sebagai berikut. Pertama data yang telah dikumpulkan melalui simak dan pencatatan kemudian ditranskrip ke dalam bentuk transkripsi kumpulan pantun. Kedua, mengelompokan pantun-pantun yang memiliki struktur yang berbeda dari kaidah pantun pada umumnya. Ketiga pantun yang sudah di kelompokan kemudian dianalisis sesuai konteksnya untuk menemukan lapis bunyi, lapis arti, lapis penokohan dan fungsi.

\section{HASIL DAN PEMBAHASAN}

\section{Analisi Struktur Pantun Sanggar Bang Bens}

Pantun pada umumnya memiliki dua pokok struktur utama, yaitu sampiran dan isi. Sampiran adalah 2 larik (baris ketika dituliskan) yang berisikan hal-hal yang berkaitan dengan kehidupan sehari-hari. Jantung pantun berada pada dua larik terakhir yang dikenal sebagai isi. Pesan-pesan pada pantun melekat pada dua larik terakhir itu. Lain halnya dengan pantun betawi yang memiliki struktur yang berbeda, dengan demikian untuk membongkar dan mengetahui struktur khas dari pantun Sanggar Bang bens akan diawali dengan menganalisis struktur.

\section{Lapis Bunyi}

Bunyi dalam pantun bersifat mutlak, selain itu bunyi dalam pantun juga berperan memperdalam ucapan, menimbulkan rasa dan menimbulkan suasana yang khusus (Pradopo, 2005:22), bunyi berperan penting untuk kosa kata dalam pantun, permainan kata dalam pantun Betawi banyak diwakili dan dimengerti dari penekanan kata yang didengar.

Penekanan-penekanan bunyi yang harmonis antara sampiran dan isi disebabkan oleh struktur akhiran suku kata Pantun Betawi yaitu AB-AB yang diucapkan oleh Centeng atau jagoan saat Palang-Pintu sedang berlangsung. Bunyi juga merupakan unsur pembangun rasa percaya diri Centeng atau jagoan. Unsur-unsur bunyi yang penting dalam analisis ini yaitu sebagai berikut.

1). Asonansi 
Asonansi adalah pengulangan bunyi vokal dalam deretan kata seperti terihat dalam vokal yang dicetak tebal pada bait-bait berikut ini.

Pantun ke-1

Sampiran : Kage salah lo tanem ari-ari kage ade lampunye,

Isi : $\quad$ kage salah lo dateng kemari ama rombongan, tapi mpok nuraini udeh ade yang punye.

Pantun Ke-2

Sampiran : Pegike Cikini mampir ke Senayan,

Isi : gue bilangin lagi ame lo mending lo angkat kaki dari sini, daripada satu rombongan gak kesampean.

Pantun Ke-3

Sampiran : Ke tanah Abang beli sekoteng

Isi : yok kite hantem-hanteman yok

Pantun ke-4

Sampiran : Uwe-uwe suara tekiber

Isi : $\quad$ Muke lu tue bibir lu jember

Pantun ke-5

Sampiran : Pak-pak-pak ding-ding-ding

Isi $\quad$ : $\quad$ Pala lu dempak idung lu miring

Panatun ke-6

Sampiran : Kentang bukan sembarang kentang

Kentang diambil dari Kwitang

Coba-coba lu nantang

Isi : Jasad lu telentang, gua masukin ke kurung batang

Muke lu gue tutupin kutang

2). Aliterasi

Aliterasi adalah pengulangan bunyi konsonan dalam deretan kata seperti pada apitan tanda kurung pada pantun dibawah ini. Aliterasi berfungsi mendekatkan kata-kata lepas dari hubungan semantik biasa. Selain itu aliterasi menekankan struktur ritmik sebuah larik dan memberi tekanan tambahan kepada kata-kata yang bersangkutan (luxemburg, 1984 : 196). Dalam Wikipedia Aliterasi merupakan pengulangan huruf mati pada beberapa suku-kata yang berturut-turut, biasanya suku-kata awal setiap kata. Aliterasi merupakan 
salah satu unsur pembentuk irama sajak awal untuk mendapatkan efek kesedapan bunyi (id.wikipedia.org/wiki/Aliterasi)

Pantun ke-1 : $\quad$ Kage salah lo tanem ari-ari kage ade lampunye,

kage salah lo date(ng) kemari ama rombo(ng)an,

tapi mpok nuraini udeh ade yang punye.

Pantun ke-2 : $\quad$ Pegi ke Cikini mampir ke Senayan,

gue bila(ng)in lagi ame lo mendi(ng) lo a(ng)kat kaki dari

sini, daripada satu rombong(an) gak kesampean.

Pantun ke-3 : $\quad$ Ke tanah Aba(ng) beli sekote(ng)

yok kite hantem-hanteman yok

Pantun ke-4 : Uwe-uwe suara tekiber

Muke lu tue bibir lu jember

Pantun ke-5 : $\quad$ Pak-pak-pak di(ng)-di(ng)-di(ng)

Pala lu dempak idu(ng) lu miri(ng)

Pantun ke-6 : $\quad K e n t a(n g)$ bukan sembara(ng) kenta(ng)

Kenta(ng) diambil dari Kwita(ng)

Coba-coba lu nanta(ng)

Jasad lu telenta(ng), gua masukin ke kuru(ng) bata(ng)

Muke lu gue tutupin kuta(ng)

3). Rima

Rima adalah pengulangan bunyi berselang, baik dalam larik maupun pada akhir larik sajak yang berdekatan. Fungsi rima bukan sekedar hiasan bunyi melainkan juga sebagai keindahan, penegasan maksud, kelancaran bunyi, membangun bait dan memudahkan menghafal sajak. Rima dalam pantun Betawi memiliki bermacam-macam Rima sebagai berikut:

Pantun ke-1

Kage salah lo tanem ari-ari kage ade lampunye,

kage salah lo dateng kemari ama rombongan,

tapi mpok nuraini udeh ade yang punye.

Pantun ke-2 
Pegi ke Cikini mampir ke Senayan,

gue bilangin lagi ame lo mending lo angkat kaki dari sini,

daripada satu rombongan gak kesampean.

\section{Pantun ke-3}

Ke tanah Abang beli sekoteng

yok kite hantem-hanteman yok

Pantun ke-4

Uwe-uwe suara tekiber

Muke lu tue bibir lu jember

Pantun ke-5

Pak-pak-pak ding-ding-ding

Pala lu dempak idung lu miring

Pantun ke-6

Kentang bukan sembarang kentang

Kentang diambil dari Kwitang

Coba-coba lu nantang

Jasad lu telentang, gua masukin ke kurung batang

Muke lu gue tutupin kutang

Dari Analisis di atas di dapatkan hasil sebagai berikut

Pantun ke-1 : [e-an-e] Rima Silang

Pantun ke-2 : [an-i-an] Rima Silang

Pantun ke-3 : [ng-ok] Rima Patah

Pantun ke-4 : [er-er] Rima Terus

Pantun ke-5 : [ng-ng] Rima Terus

Pantun ke-6 : [ng-ng] Rima Terus

\section{Lapis Arti}

Pantun ke-1 diserukan oleh jawara dari pihak perempuan yang bermaksud mengalang-halangi mempelai pria dengan gamblang bahwa mempelai wanita sudah memilih laki-laki lain. 
Pantun ke-2 diserukan oleh jawara dari pihak perempuan, bermaksud mengusir rombongan mempelai laki-laki karena jawara dari mempelai perempuan merasa bisa mengalahkan jagoan dari pihak laki-laki atau memberikan tekanan mental pada jawara pihak laki-laki. Pada bait ke-tiga "daripada satu rombongan gak kesampean" bermaksud mengusir secara eksplisit.

Pantun ke-3 diserukan oleh jawara dari pihak laki-laki pada bait ke-2 "yok kite hantemhanteman yok" jawara pihak laki-laki sudah tidak sabar untuk mengajak jawara pihak perempuan untuk beradu ilmu bela diri.

Pantun ke-4 diserukan oleh jawara pihak laki-laki, arti dari pantun ini ialah jawara dari pihak laki-laki menjatuhkan mental jawara dari pihak perempuan dengan cara menyebutkan kejelekan fisik menggunakan majas Hiperbolla, karena pada kenyataanya pantun tersebut tidaklah benar.

Pantun ke-5 diserukan oleh jawara pihak perempuan, pantun ini merupakan pantun balasan dari pantun ke-4 karena jawara dari pihak perempuan tidak terima dirinya dihina secara fisik.

Pantun ke-6 diserukan oleh jawara pihak laki-laki, pantun ini merupakan pantun balasan dari pantun ke-5. Pantun ini berartikan bahwa jawara dari pihak laki-laki sudah sangat percaya diri bisa mengalahkan jawara dari pihak perempuan

\section{"Coba-coba lu nantang}

\section{Jasad lu telentang, gua masukin ke kurung batang \\ Muke lu gue tutupin kutang"}

Pada baris ke-3 berartikan jawara pihak laki-laki memperingatkan jawara pihak perempuan pasti bisa mengalahkannya, lalu pada baris ke-4 dan ke-5 jawara dari pihak laki-laki menekankan jika jawara dari pihak perempuan akan kalah (mati) maka ia akan mempermalukan jasad jawara dari pihak perempuan dengan menutupi jasad jawara pihak perempuan dengan kaos kutang miliknya.

\section{Lapis Penokohan}

1. Tokoh Jawara ialah tokoh yang disegani masyarkat Betawi kerena berwibawa, bijaksana dan pelindung kampung dari orang-orang yang jahat karena memiliki keahlian bepantun dan pencak silat

2. Mempelai laki-laki dan peremuan merupakan tokoh utama disetiap prosesi PalangPintu 
3. Pembaca Sike atau Shalawat Dustur atau penyeru pujian-pujian nabi dalam ajaran Agama Islam yang dianut mayoritas masyarakat Betawi, Penyeruan Sike adalah penandaan bahwa prosesi Palang Pintu sudah selesai.

\section{Gaya Bahasa}

- Pantun ke-1 baris pertama dan baris kedua mengandung majas pararelisme, atau pengulangan kata;

Kage salah lo tanem ari-ari kage ade lampunye,

kage salah lo dateng kemari ama rombongan,

sedangkan dalam bait ketiga mengandung majas metafora atau seolah-olah tokoh dalam pantun merupakan sebuah barang kepunyaan,

tapi mpok nuraini udeh ade yang punye.

- Pantun ke-2, baris kedua mengandung majas eufemisme atau memperhalus maksud untuk mengusir, gue bilangin lagi ame lo mending lo angkat kaki dari sini,

pada baris ke-3 mengandung majas Sarkasme atau menyampaikan maksud secara kasar,

daripada satu rombongan gak kesampean.

- Pantun ke-3, baris kedua mengandung majas dualis, yaitu majas eufemisme dan sarkasme, majas eufemisme tidak menggunakan kata "pukul-pukulan" melainkan kata "hantam" namun dengan selipan majas sarkasme yaitu menyampaikan sindiran seca kasar.

yok kite hantem-hanteman yok.

- Pantun ke-4 baris kedua mengandung majas dualis yaitu majas sarkasme dan majas hiperbola, penggunaan kata "Jember" dalam KBBI berarti kotor dan lembab.

Muke lu tue bibir lu jember

- Pantun ke-5 baris kedua mengandung majas sarkasme, penggunaan kata "dempak" dan "miring" mewakilkan majas sarkasme.

\section{Pala lu dempak idung lu miring}

- Pantun ke-6 baris pertama mengandung majas metafora yang bermaksud sebuah kentang yang bisa melakukan hal tidak biasa. Lalu pada baris ketiga dan keempat mengandung majas sarkasme.

\section{Kentang bukan sembarang kentang}

Kentang diambil dari Kwitang

Coba-coba lu nantang 
Jasad lu telentang, gua masukin ke kurung batang

Muke lu gue tutupin kutang.

\section{Analisis Fungsi Pantun Sanggar Bang Bens Sebagai Alat Pemaksa dan Pengawas Norma-Norma Masyarakat}

Sastra lisan berfungsi sebagai alat pemaksa dan pengawas norma-norma masyarakat. Dalam pantun Sanggar Bang Bens terselip makna dan amanat yang mengawasi norma-norma secara tidak langsung. Norma moral yang itensitasnya tinggi terdapat dalam pantun-pantun Sanggar Bang Bens.

Norma moral adalah tolak ukur yanga dipakai oleh masyarakat untuk mengukur kebaikan seseorang dalam bermasyarakat, maka dengan norma moral kita betul-betul dinilai. Itulah sebab penilaian moral selalu berbobot. Pesan moral sastra lebih memberat pada sifat kodrati manusia yang hkiki, bukan para aturan-aturan yang dibuat, ditentukan, dan dihakimi oleh manusia (Nurgiyantoro, 2007: 323).Norma moral dapat ditemukan dalam beberapa pantun Sanggar Bang Bens sebagai berikut;

Makan sekoteng di pasar Jumat, mancing lele jauh di Kramat Jati.

saye datang dengan segala hormat, mohon kirenye diterima dengan senang hati.

\section{Bang!, Kalo lo makan ketupat disiang hari,}

e! Jangan lupe semur tahunye.

kalo lo dateng same rombongan jauh-jauh dateng kemari, gue mau tau ape hajatnye.

Norma moral dapat ditemukan secara tidak langsung pada pantun pertama dan kedua. Pantun pertama memiliki pesan bahwa ketika kita datang menjadi seorang tamu hendaknya mengucap salam dan menjunjung tinggi kesopanan dalam bertamu. Pantun kedua secara tidak langsung memiliki pesan bahwa setiap tamu selayaknya disambut dengan baik dan tuan rumah menanyakan tujuannya secara baik pula.

\section{Sebagai Alat Pemaksa Pendidikan Anak-Anak}

Pantun dikehidupan bermasyarakat suku Betawi memiliki tempat yang istimewa. Dalam hal ini pantun membuat anak-anak menjadi leih aktif, kreatif dan percaya diri. Proses kreatif yang terjadi ketika penciptaan pantun bagi anak-anak akan meningkatkan IQ, sehingga melalui pantun seorang anak akan dapat bertindak lebih efisien untuk mendapatkan hasil yang lebih baik dari sebelumnya. Dengan demikian, secara tidak langsung anak-anak akan memperoleh keterampilan bernalar, keterampilan untuk 
mengucapkan kata-kata yang indah dan kepercayaan diri yang membuat pengetahuan kekayaan gerak yang didapat dari tradisi Palang Pintu. Kelugasan, apa adanya mengalir begitu saja dalam pantun Betawi dan hiburan juga membuat anak-anak menjadi jujur pada dirinya dan orang lain.

Anak-anak yang diikutsertakan oleh orangtuanya untuk mengikuti tradisi Palang Pintu tidak hanya mendapat hiburan dan pesan moral saja. Lebih luas lagi anak-anak akan memiliki rasa keingintahuan yang tinggi untuk mempelajari dan mengetahui secara luas tentang pantun, unsur Pencak Silat dalam tradisi Palang Pintu juga membuat anakanak mempunyai rasa kepahlawanan dalam diri untuk melindungi dirinya dan orang lain. Sejalan dengan pernyataan diatas regenarasi untuk menjadi seorang Jawara sangat diperlukan untuk menjaga eksistensi tradisi Palang Pintu, sehingga pentingnnya mewariskan tradisi Palang Pintu kepada anak-anak.

\section{Fungsi Hiburan}

Sastra lisan tidak harus tergantung pada beberapa sifat-sifat atau pemanen dalam teks, tetapi pada lingkungan tempat sastra lisan tersebut disampaikan serta sifat dan harapan khlayak penikmat (Finnegan via Sudikan, 2001: 115). Pantun Betawi memiliki ciri yang bebas tidak terikat oleh strukur dan mengalir begitu saja, sejalan dengan pernyataan tersebut Pantun Sanggar Bang Bens memiliki unsur banyolan yang terdapat dalam pantun itu sendiri atau tingkah pembawaan Jawara saat menyerukan pantun dan biasanya diikuti oleh gelak tawa penonton, berikut adalah beberapa contoh pantun Sanggar Bang Bens yang memiliki unsur hiburan;

\section{Uwe-uwe suara tekiber}

Muke lu tue bibir lu jember

\section{Pak-pak-pak ding-ding-ding}

Pala lu dempak idung lu miring

\section{Kentang bukan sembarang kentang}

Kentang diambil dari Kwitang

Coba-coba lu nantang

Jasad lu telentang, gua masukin ke kurung batang

Muke lu gue tutupin kutang

\section{Jalan-jalan ke tepi muara}

Naik metromini disangka maling

Baju lo boleh jawara 


\section{Semalem lo pake rok mini sama legging}

Respon masyarakat terhadap penyampaian pantun di atas secara sadar maupun tidak menimbulkan reaksi yang membuat masyarakat mereflesikan kelucuan dari para jawara dan menertawakannya.

\section{Fungsi Religius}

Pantun Sanggar Bang Bens memiliki fungsi religius yang tinggi karena beberapa pantun Sanggar Bang Bens terkandung makna tentang berkehidupan dengan fitrah kepada penciptanya serta permohonan kepada pencipta. Seruan Sike atau pujian kepada nabi-nabi dalam agama islam pada akhir prosesi Palang Pintu memiliki fungsi religius yang tinggi. Berikut adalah Sike yang biasa diserukan;

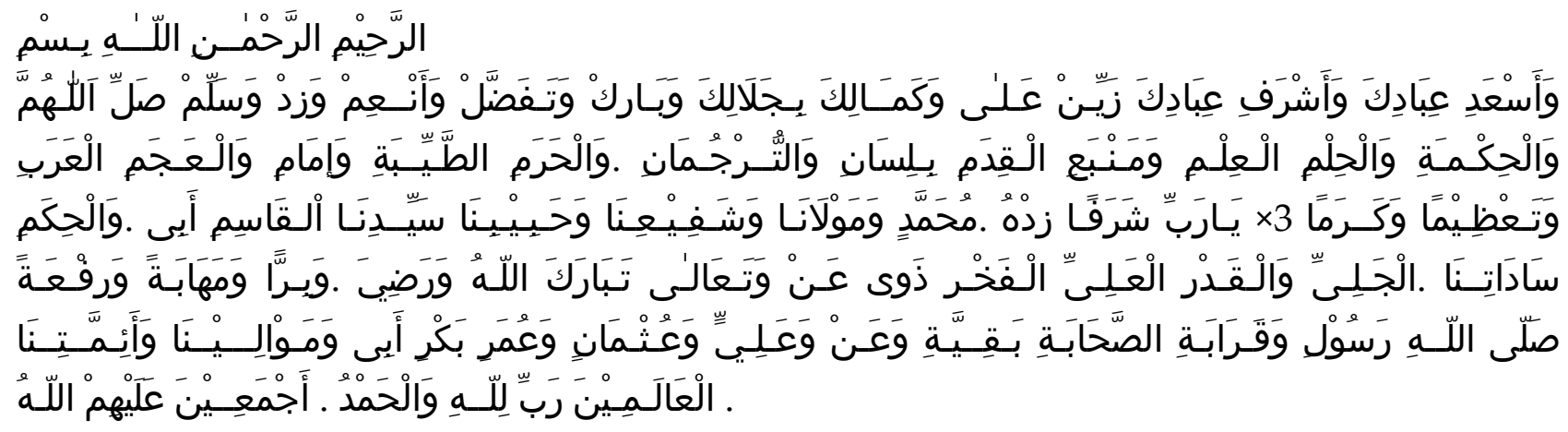

“Dengan menyebut Nama Allah Yang Maha Pengasih lagi maha Penyayang. Ya Allah ! limpahkanlah shalawat dan keselamatan, tambahkan, berikanlah keselamatan, berikanlah keutamaan dan limpahkanlah keberkahan, dengan segala kemuliaan dan kesempurnaanMu yang paling Agung, orang Arab dan orang 'Ajam yang paling beruntung pemimpin segala kebaikan dan kemuliaan, penerjemah dengan lisan yang paling unggul, sumber ilmu pengetahuan, kesabaran, hikmah dan kearifan, yakni Abul Qasim, pemimpin kami, kekasih kami, pemberi syafaat kami, dan tuan kami Muhammad saw. Tambahkanlah kepadanya keluhuran wahai Tuhanku 3x. Juga kemuliaan, keagungan, ketinggian derajat, kehebatan dan kebaikan. Semoga Allah Yang Maha Memberkati dan Maha Mulia senantiasa Meridloi sang pemilik keagungan yang tinggi, kekuasaan yang nyata, para pemimpin imam dan pemuka-pemuka kami, Abu Bakar, Umar, Utsman, dan 'Ali. Juga seluruh sahabat dan kerabat Rasulullah. Semoga Allah senangtiasa melimpahkan rahmatnya kepada beliau dan kepada seluruh sahabat dan keluarganya. Segala pujin bagi Allah. Tuhan semesta alam".

\section{SIMPULAN}


Pantun-pantun Sanggar Bang Bens memiliki makna mendalam tentang berkehidupan dengan norma-norma yang berlaku di maysarakat. Pantun-pantun sanggar Bang Bens memiliki ciri dan kompleksitas struktur yang khas. Unsur-unsur keunikan tersebut meliputi lapis bunyi, lapis arti, lapis penokohan dan gaya bahasa

Pantun sanggar Bang Bens memiliki keunikan dengan gaya cirikhas tersendiri yaitu;

1. Bunyi asonansi pada setiap bait pantun sanggar Bang Bens memiliki peran yang dominan, baik asonansi vokal yang bersuara berat a dan u maupun asonansi vokal yang bersuara ringan seperti i,e dan o.

2. Aliterasi pada tiap-tiap pantun sanggar Bang Bens ditemukan konsosnan nassal (ng) yang dominan digunakan oleh anggota sanggar Bang Bens.

3. Rima silang dan Rima Terus adalah rima yang dominan yang ditemukan dalam pantun Sanggar Bang Bens.

4. Jawara adalah tokoh yang dipilih dari masing-masing kedua mempelai untuk menyerukan pantun dan beradu ilmu bela diri.

5. Audiens adalah tokoh yang menjadi saksi pelaksanaan tradisi Palang Pintu, audiens tidak dibatasi oleh usia dan status sosial.

\section{DAFTAR PUSTAKA}

Belajar Giat Id. (Diakses pada 21 April 2021 dari alamat https://belajargiat.id/pantun/). Chaer, Abdul. 2012. Folklor Betawi. Jakarta: Masup.

Danandjaja, James. 1986. Folkor Indonesia, ilmu gosip, dongen dan lain-lain. Jakarta: Erlangga.

Ensiklopedi Portal Resmi Provinsi DKI Jakarta. (Diakses pada 17 Febuari 2021 dari alamat jakarta.go.id/artikel/konten/pantunbetawi).

Guntar, Elista Lisnawati. 2011. Analisis Struktur dan Fungsi Puisi Lisan Torok Cear Cumpe dan Torok we'e Mbaru. Dalam skripsi Fakultas Ilmu Budaya: Universitas Udayana.

Hadur, Michael. 2000. Fungsi Puisi Lisan Daleng Manggarai. (Skripsi). Denpasar: Universitas Udayana.

Lahama, Theodorus Budiarjo. 2018. Mengenal Palang Pintu Tradisi Orang Betawi. $\begin{array}{llllll}\text { (Diakses } & \text { pada } & 18 & \text { Febuari } & 2021 & \text { dari amat }\end{array}$ muda.kompas.id/baca/2018/07/04/mengenal palang pintu tradisi orang Betawi)

Luxmburg, Jan Van Dkk. 1984. Pengantar Ilmu Sastra. Jakarta: PT. Gramedia Pustaka Utama.

Mahayana, Maman. 2013. Pantun sebagai Potret Sosial-BudayaTempatan: Pantun Melayu, Jawa, Mdura, dan Betawi. dalam Jurnal Kritik. Vol. 04. 2013 h.85-100.

Mahsun. 2017. Metode Penelitian Bahasa. Depok: PT. Raja Grasindo Persada

Nurgiyantiro, Burhan. 2007. Pengkajian Fiksi. Yogyakarta: Gajah Mada University Press.

Pradopo, Rachmat Djoko. 2005. Pengkajian Puisi. Yogyakarta: Gadjah Mada University Prees. 
Puspitasari, Siti Rojab dian. 2008. Pantun Betawi dalam siaran Bensradio: Tinjauan Fungsi dan Amanat. dalam skripsi Fakultas Ilmu Pengetahuan Budaya: Universitas Indonesia.

Ratna, Nyoman Kutha. 2009. Teori, Metode, dan Teknik Penelitian Sastra: dari Strukturalisme Hingga Postrukturalisme. Yogyakarta: Pustaka Pelajar.

Santoso, Puji.1996. Pengetahuan dan Apresiasi Kesusastraan dalam Tanya Jawab. Ende: Nusa Indah.

Saputra, Yahya Andi. 2008. Upacara Daur Hidup Adat Betawi. Jakarta: Wedatama Wedya Sastra.

Sari, Rostina. 2013. Representasi Budaya Pantun Betawi dalam tayangan Pesbukers di Antv Tahun 2013 dalam skripsi Fakultas Ilmu Sosial dan Politik: Universitas Muhamadiyah Yogyakarta.

Semi, Atar. 1989. Kritik Sastra. Bandung: Angkasa.

Sudikan, Setya Yuwana. 2001. Metode Penelitian Sastra Lisan. Surabaya: Citra Wacana.

Sukada, Made. 1987. Beberapa Aspek Tentang Sastra. Denpasar: Kayumas dan Yayasan Ilmu Seni dan Lebisa.

Tassai, S Amran. 1991. Telaah Susastra Melayu Betawi. Jakarta: Departemen Pendidikan dan Kebudayaan

Taum, Yoseph Yapi. 2011. Studi Sastra Lisan Sejarah, Teori, Metode dan Pendekatannya Disertai Contoh Penerapannya. Yogyakarta: Lamalera.

Teeuw, A. 1994. Indonesia antara Kelisanan dan Keberaksaraan. Jakarta: Pustaka Jaya.

Wardah, Indah. 2015. Struktur Pantun Pada Seni Budaya Palang Pintu Betawi dan Implikasinya Terhadap Pembelajaran Sastra Indonesia di SMP dalam skripsi Fakultas Ilmu Tarbiyah dan Keguruaan: Universitas Syarif Hidayatullah Jakarta.

Wellek, Rene dan Austin Warren. 1989. Teori Kesusastraan. Jakarta: PT. Gramedia pustaka Umum.

Wikipedia Bahasa Indonesia, Ensiklopedia bebas. (Diakses pada 20 April 2021 dari alamat id. wikipedia.org/wiki/Aliterasi).

Wikipedia Bahasa Indonesia, Ensiklopedia bebas. (Diakses pada 20 April 2021 dari alamat id.wikipedia.org/wiki/Fungsi).

Wikipedia Bahasa Indonesia, Ensiklopedia bebas. (Diakses pada 19 Oktober 2020 dari alamat id.wikipedia.org/wiki/Tradisi).

Wikipedia Bahasa Indonesia, Ensiklopedia bebas. (Diakses pada 19 Oktober 2020 dari alamat id.wikipedia.org/wiki/konsep).

Wikipedia Bahasa Indonesia, Ensiklopedia bebas. (Diakses pada 18 Febuari dari alamat id.wikipedia.org/wiki/puisi_lama).

Wikipedia Bahasa Indonesia, Ensiklopedia bebas. (Diakses pada 18 Febuari dari alamat id.wikipedia.org/wiki/Palang_Pintu).

Windoro, Adi. 2010. Batavia 1740 Menyisir Jejak Betawi. (Diakses pada 23 Febuari 2021 dari alamat kumparan.com/potongan/asal-usul/rawa-belong).

Yudono K-S, 1986. Telaah dan Kritik Sastra Indoneisa. Bandung: Angkasa 


\section{PROFIL PENULIS}

Muhammad Dwi Juniarto adalah mahasiswa Prodi Sastra Indonesia tahun 2016. Sejak jenjang Sekolah Menengah Atas ia sudah mulai aktif di berbagai kegiatan sastra, tahun 2015 ia memenangkan juara lomba baca puisi tingkat pelajar pada gelaran lomba baca puisi tingkat pelajar se- Jakarta, lalu tahun 2017 saat masuk perguruan tinggi di Universitas Udayaba dia meraih juara pertama lomba musikalisasi tingkat provinsi Bali. 